\title{
Sensor Óptico de Corrosão para Poços de Petróleo
}

Andrade, R. A. L. de

Escola Politécnica de Pernambuco

Universidade de Pernambuco

50.720-001 - Recife, Brasil

renato0807@gmail.com
Nacimento, J. F.

Escola Politécnica de Pernambuco

Universidade de Pernambuco

50.720-001 - Recife, Brasil

jehan@poli.br

Resumo Neste trabalho é apresentado um sistema para determinação da taxa de corrosão de metais à base de fibra óptica monomodo utilizando a técnica de reflectometria óptica no domínio do tempo. Os experimentos em laboratório simula-se a corrosão através da imersão de uma fina camada de alumínio depositada numa fibra em uma solução ácida conhecida e medindo no OTDR a variação do nível de luz refletida ao longo do tempo. Trata-se de um sistema auto-referenciado, multiponto, que não possui partes móveis e que é capaz de determinar a taxa de um ponto a quilometros de distância do centro de monitoramento e que, por esses motivos, se mostra ideal para aplicação em poços de petróleo de grande profundidade.

Abstract In this work is presented an optical fiber system for determination of corrosion rate of metal using optical time domain reflectometry technique. Laboratory experiments simulate corrosion through immersion of a thin aluminum layer deposited on fiber facet into a known acid solution and measuring on the OTDR the reflected light level variation through the time. It is an auto-referenced, multi-point system, that does not have mobile parts and it is capable of determining corrosion rate kilometers away from monitoring centre. For these reasons, it appears to be ideal for application at great depth oil wells. 


\section{Introdução}

A atividade de extração de petróleo é uma atividade da qual se extraem lucros milionários. Porém, o risco de um vazamento representa um motivo de grande preocupação, considerando suas consequências, que são claramente observadas tanto na esfera econômica quanto na ambiental, com prejuízos financeiros e ao meio ecossistema local, respectivamente, sendo ambos de grandes proporções. A manutenção também requer milhões de dólares para ser executada [1]. Por esse motivo, e pelo fato de as condições de temperatura e pressão serem mito grandes e as distâncias envolvidas serem quilométricas, trata-se de um desafio da atualidade desenvolver um sistema de controle de corrosão eficiente, que verifique quando e onde há a necessidade de realizar manutenção.

As fibras ópticas apresentam características que as tornam ideais para serem empregadas no ambiente hostil dos dutos de petróleo [2]. Elas são simples, versáteis, seguras, confiáveis e de pequenas dimensões. Além disso, não estão sujeitas a ruídos eletromagnéticos externos, por serem materiais isolantes, não apresentam perdas significativas de sinal quando os transportam por longas distãncias e podem ser utilizadas para fabricar redes de sensores. As vantagens são muitas, porém, hoje ainda há limitações como o desenvolvimento de sistemas que se utilizam apenas de fibras de multímodo especial, que se valem de partes móveis, comprometendo parte da robustez do sistema, ou sistemas monoponto [3].

Este trabalho se propõe a apresentar a concepção e demonstração experimental de um sistema sensor de corrosão a base de fibra óptica que utiliza a técnica de reflectometria óptica no domínio do tempo (OTDR). Este sistema é multiponto, auto-referenciado, não possui partes móveis, e pode determinar a corrosão a quilômetros de distância do equipamento OTDR. Apresentam-se aqui os resultados obtidos em condições controladas de laboratório para a determinação da taxa de corrosão do metal.

\section{Materiais e Descrição do Sistema Sensor}

O sistema utilizado, representado na Figura 1, consiste em 11 cabeças sensoras, sobre as quais foi depositada uma fina camada de alumínio através do processo de evaporação térmica, acopladas a uma única fibra monomodo de 2 $\mathrm{km}$ que recebe um sinal do aparelho OTDR. Este envia o sinal, que percorre toda a fibra, e depois mensura o sinal refletido ao longo de todos os pontos para o qual. Foi ajustado para medir. Escolhendo dois pontos, pode-se, além de observar, quantificar, em decibéis, a diferença do sinal refletido entre eles.

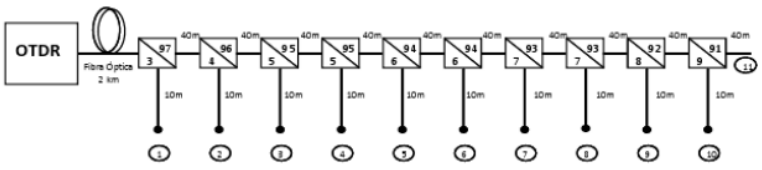

Figura 1. Diagrama esquemático representando o sistema sensor utilizado. São mostradas as 11 cabeças sensoras Figura 1. Diagrama esquemático representando o sistema sensor utilizado. São mostradas as 11 cabeças sensoras
numeradas, o comprimento das porçôes de fibra optica monomodo e as porcentagens de derivaçăo dos acopladores opticos.

O aparelho é um Anritsu 9076B, o comprimento de onda em que ele opera é $1,55 \mu \mathrm{m}$ e tem uma largura de pulso de $10 \mathrm{~ns}$, o que corresponde a uma resolução espacial de $2 \mathrm{~m}$. O OTDR foi ajustado para medir 5000 pontos numa distância de $5 \mathrm{~km}, \operatorname{logo}$, um ponto a cada $10 \mathrm{~cm}$. O sinal gerado pelo OTDR é direcionado para cada cabeça sensora através de acopladores posicionados ao longo da fibra, que desviam uma porcentagem de 3 a $9 \%$ do sinal que percorre a fibra no ponto em que está instalado.

\section{Resultados e Discussão}

A cabeça de número 6 foi utilizada para os experimentos de simulação de corrosão controlada em laboratório cada pico no traço do OTDR corresponde a uma cabeça sensora; logo o sexto pico corresponde à sexta cabeça sensora (Figura 2). O alumínio depositado na ponta da fibra foi imerso na solução ácida $25 \mathrm{H} 3 \mathrm{PO} 4: 1 \mathrm{HNO} 3: 5$ $\mathrm{CH} 3 \mathrm{COOH}$, que é bem conhecida. Sabe-se que a taxa de corrosão desse ácido para o alumínio é de $50 \mathrm{~nm} / \mathrm{min}$. Como a reflectância da luz sobre o metal depende da espessura deste, de modo que, à medida que a espessura diminui, mais luz consegue atravessá-lo, é possível visualizar, através dos dados obtidos pelo OTDR e após certo tempo de corrosão, a diminuição da espessura do alumínio quando ele é imerso na solução ácida (Figura 3).

A intensidade é medida quando, após ser retirada do ácido, a ponta da fibra é imersa na água. Analisando o gráfico obtido com o experimento (Figura 4), pode-se resumilo em quatro etapas: um primeiro patamar, onde ocorre corrosão mas esta não provoca redução na reflectância; uma queda de inclinação aproximadamente constante após os primeiros 60 segundos de corrosão; depois o alcance de um valor mínimo, um pequeno aumento nos valores medidos; e o estabelecimento de um novo patamar, aproximadamente após $120 \mathrm{~s}$ de experimento, que corresponde à corrosão completa do alumínio. O primeiro patamar ocorre porque a espessura ainda é suficientemente grande para que todo o sinal seja refletido. Após $60 \mathrm{~s}$ de corrosão, a espessura já não é tão grande, provocando redução da reflectância com a diminuição da espessura. $\mathrm{O}$

último patamar acontece porque, após a corrosão total do alumínio, o nível de reflexão da luz medido é o da interface fibra-líquido, o qual é constante em função do tempo. O 
vale observado antes do segundo patamar não tem importância na determinação da taxa de corrosão, logo não é objeto de estudo deste trabalho.

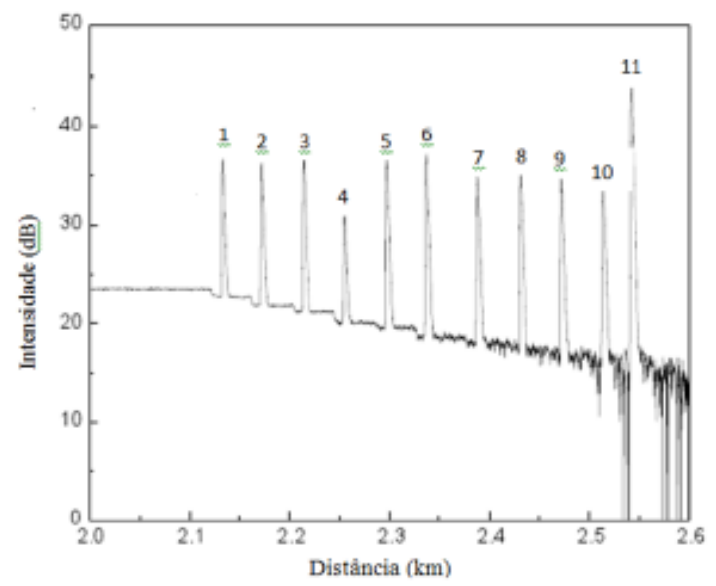

Figura 2. Traço do OTDR correspondendo à intensidade da luz refletida para cada ponto. Cada pico de reflexão corresponde a uma cabeça sensora.

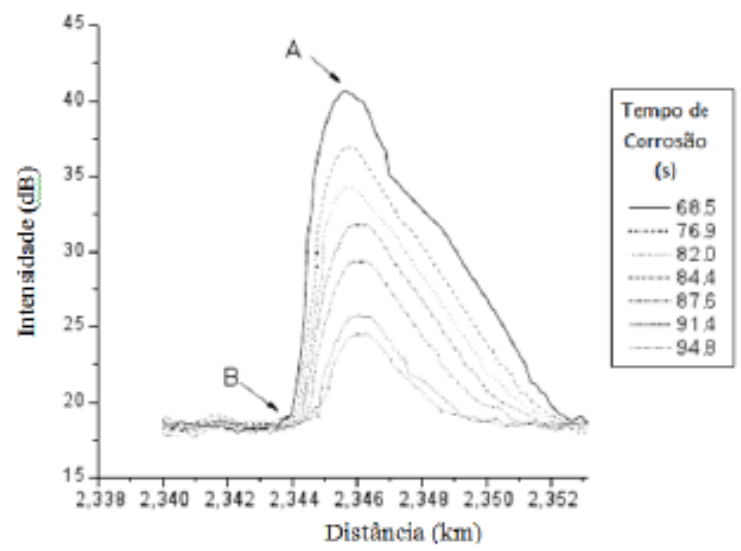

Figura 3. Traço do OTDR para a cabeça sensora número 6 , para vários tempos de corrosão.

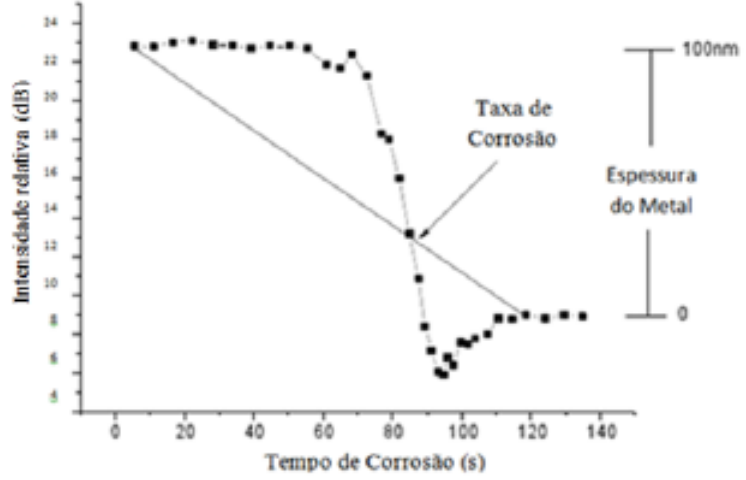

Figura 4. Intensidade relativa medida ao longo do processo de corrosão do alumínio. É indicada a reta utilizada para o cálculo da taxa de corrosão e por meio da qual se identificam os pontos utilizados marcados como início e fim do processo.

Calculamos a taxa de corrosão dividindo a espessura total no início do experimento pelo tempo necessário para atingir o patamar inferior. Esse cálculo nos dá a taxa de $47,5 \mathrm{~nm} / \mathrm{min}$, que apresenta um erro de apenas $5 \%$ em relação à taxa esperada de $50 \mathrm{~nm} / \mathrm{min}$.

O modo de obtenção da taxa de corrosão, pela razão entre o sinal detectado nos pontos A e B (Figura 2), confere ao sistema a característica de ser auto-referenciado, ou seja, não sofrer influência de eventuais flutuações devido a curvatura das fibras, variações na intensidade do sinal emitido pelo OTDR ou nas características dos acopladores ópticos.

\section{Conclusões}

Neste trabalho foi proposto um sistema de monitoramento de corrosão metálica à base de fibra óptica e demonstrado experimentalmente o processo de determinação da taxa de corrosão de um metal depositado na face de uma fibra através da técnica de reflectometria óptica no domínio do tempo. Os resultados apresentaram um erro considerado pequeno, de $5 \%$, em relação à taxa esperada.

O sistema é auto-referenciado, não possui partes móveis, é multiponto e é capaz de determinar a taxa de corrosão a quilômetros de distância, pois foi feito com o propósito de aplicação nas condições físicas hostis dos dutos de petróleo, onde é de fundamental importância evitar acidentes e, ao mesmo tempo, é desaconselhável parar a produção para realizar manutenção apenas por prevenção, considerando os prejuízos financeiros provocados por interrupções na produção e até ambientais, no caso de vazamentos. Vale ressaltar que, apesar de ter sido utilizado alumínio para a simulação de corrosão, outros metais de interesse podem ser utilizados. 


\section{Agradecimentos}

Agradecemos à Escola Politécnica de Pernambuco pelo seu programa de Iniciação Científica, ao Departamento de Eletrônica e Sistemas da UFPE pela concessão de seu espaço e estrutura para realização das pesquisas e a FACEPE pelo apoio financeiro.

\section{Referências}

[1] CLARK, K., SCHILLING, L., Fiber Optic Sensor Suite for Corrosion and Flow-Assurance Monitoring in Deepwater Flowlines, 2001, em http://jazz.nist.gov/atpcf/prjbri-

efs/prjbrief.cfm?Proj ectNumber=00-00-4611

[2] QIAO, G., ZHOU, Z., OU, J., Thin Fe-C Alloy Solid Film Based Fiber Optic Corrosion Sensor, Proc. Of the 1st IEEE International Conference on Nano/Micro Engineered and Molecular Systems, 2006, China, pp. 541-544.

[3] STAVELEY, C., Applications of Optical Fibre Sensors to Structural Health Monitoring, Optimisation and Life-cycle Cost Control for Oil and Gas Infrastructures, Business Briefing: Exploration \& Production: The Oil \& Gas Review 2004, e ttp://www.bbriefings.com/pdf/951/smart_tech.p 